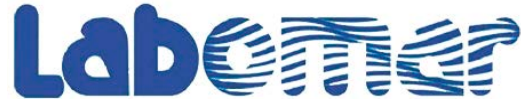

\section{ANÁLISE DA EVOLUĢ̃̃o DO SETOR PESQUEIRO DE PERNAMBUCO}

\author{
Analysis of the evolution of the Pernambuco \\ fishery sector \\ Severino Adriano de Oliveira ${ }^{1}$, Lima Humber Agrelli Andrade ${ }^{2}$ \\ 1 Doutorando em Recursos Pesqueiros e Aquicultura da Universidade Federal Rural de Pernambuco (UFRPE). \\ Bolsista CAPES E-mail: dianooliveira@hotmail.com \\ 2 Professor Adjunto do Departamento de Pesca e Aquicultura da Universidade Federal Rural de Pernambuco (UFRPE). \\ Av. Dom Manoel de Medeiros s/n. Dois Irmãos, Recife - Pernambuco. CEP: 52171900
}

\begin{abstract}
RESUMO
Informações são à base de um manejo racional, estando por trás de todos os estágios da administração dos recursos pesqueiros. Neste trabalho foi analisada a evolução do setor pesqueiro no litoral de Pernambuco, a partir de um recorte histórico da atividade para o período de 1999 a 2006. As informações analisadas neste trabalho foram extraídas dos relatórios de produção de pescado marítimo e estuarino do Estado de Pernambuco, publicados nos boletins do CEPENE. Os dados foram estratificados por ano, município, tipo de embarcação, arte de pesca e categoria específica do pescado, para posterior análise descritiva e inferências não paramétricas. Os resultados mostram que as capturas dos anos 2005 e 2006 foram marcantemente maiores que nos outros anos. Em geral, as capturas de Itapissuma e Goiana foram maiores que as das demais cidades. Das quinze Famílias responsáveis pelas capturas, nove delas pertencem ao grupo de peixes (Engraulidae, Mugilidae, Haemulidae, Mullidae, Carangidae, Lutjanidae, Scaridae, Scombridae e Clupeidae). As capturas de Pernambuco mostraram-se amplamente baseadas em recursos pesqueiros estuarinos situados em baixos níveis da cadeia trófica, especialmente na costa norte.
\end{abstract}

Palavras-chave: pesca de pequena escala, coleta manual, desembarque pesqueiro.

\section{ABSTRACT}

Information is required for the rational management, which gives support to all stages of fisheries management. In this paper the evolution of the fishing sector in the coast of Pernambuco was

Recebido em: 03/03/2018

Aprovado em: 10/12//2018

Publicado online em: 25/03/2019 
analyzed, based on a history of activity between 1999 and 2006. The information analyzed in this paper was gathered from the reports of production of marine and estuarine fish of the State of Pernambuco, published in the CEPENE bulletins. The data were stratified by year, municipality, type of vessel, fishing gear and fish category, for later making descriptive analysis and nonparametric inferences. The catches in 2005 and 2006 years were remarkedly higher than in other years. The catches of Itapissuma and Goiana were higher than in the other cities. Fifteen families support most of the catches. Among fifteen families responsible for catches, nine of them belonged to the fish groups (Engraulidae, Mugilidae, Haemulidae, Mullidae, Carangidae, Lutjanidae, Scaridae, Scombridae and Clupeidae. The catches of Pernambuco have been largely based on estuarine fisheries resources held on the low levels of the food chain, especially in the north coast.

Key words: small scale fisheries, manual collection, fisheries statistics.

\section{INTRODUÇÃO}

O monitoramento da atividade pesqueira do Brasil, assim como em vários países subdesenvolvidos, não dispõe de séries temporais de capturas cobrindo longo período de tempo, devido a descontinuidade dos planos de coleta de informações do setor pesqueiro, o que dificulta a tomada de decisão para gestão dos recursos pesqueiros. Programas de monitoramento da pesca geram informações importantes sobre os efeitos da exploração na composição e na densidade dos recursos pesqueiros (Shepherd, 1984).

Dessa forma, o monitoramento auxilia o processo de tomada de decisão e a implementação de medidas de controle que visam manter o recurso em níveis razoáveis para a sobrevivência da atividade pesqueira (Policansky, 1998). Dados e informações são a base para um gerenciamento pesqueiro eficiente, o qual depende dos processos envolvidos na administração, formulação de políticas, elaboração dos planos de manejo, avaliação e atualização contínua das políticas do setor (Fao, 2003).

No Estado de Pernambuco, assim como no restante do Brasil, os dados sobre a pesca disponíveis para consulta pública abrangem o período de 1999 a 2011, porém, apenas os anos entre 1999 e 2006 possuem informações completas de interesse para essa pesquisa (e.g. embarcações, artes de pesca, municípios, categorias de espécies). No período em destaque, a captura dos diversos recursos pesqueiros em Pernambuco foi alvo de estudos realizados pelo Centro de Pesquisa e Gestão de Recursos Pesqueiros do Nordeste (CEPENE), instituição responsável por monitorar a produção pesqueira do Nordeste.

A maior concentração da atividade pesqueira no Brasil e também em Pernambuco está localizada na faixa litorânea. Assim, os dados sobre a pesca em Pernambuco, especialmente entre 1999 a 2006 (Ibama/Cepene, 2008, 2007, 2006, 2005, 2004, 2003, 2002, 2000), estão disponíveis para a pesca nos municípios litorâneos.

Ainda são poucos os estudos que se propõem a sistematizar os dados e informações do setor pesqueiro dos Estados nordestinos, em períodos recentes, no intuito de avaliar as tendências e especificidades produtivas dos municípios e seus territórios de pesca. A disponibilidade e qualidade dos dados do setor pesqueiro colocam-se como barreiras para as análises dessa natureza. Portanto, o objetivo deste trabalho foi o de mostrar a evolução do setor pesqueiro de Pernambuco, a partir de um recorte histórico da atividade para o período de 1999 a 2006, com intuito de contribuir para ações de gestão dirigidas aos municípios litorâneos do Estado. 


\section{MATERIAL E MÉTODOS}

\section{Área de estudo}

A zona costeira de Pernambuco tem uma faixa de $187 \mathrm{~km}$ e concentra a maior parte da população do Estado. A zona está dividia em três regiões, estando assim distribuídas: o Norte composto pelos municípios de Goiana, Itaquitinga, Itapissuma, Ilha de Itamaracá, Igarassu, Araçoiaba, Abreu e Lima e Paulista; o Centro ou Núcleo Metropolitano constituído pelos municípios de Olinda, Recife e Jaboatão dos Guararapes; e o Sul pelos municípios de Cabo de Santo Agostinho, Ipojuca, Sirinhaém, Rio Formoso, Tamandaré, Barreiros e São José da Coroa Grande. Os municípios do Centro são as três mais populosas do Estado, com destaque para a capital Recife.

As comunidades pesqueiras estão localizadas em quase todo litoral, porém em alguns municípios a pesca é considerada uma atividade predominante. Dentre esses municípios, Itapissuma tem maior dependência com relação a pesca, pois aproximadamente $60 \%$ da renda desse local depende direta ou indiretamente da atividade.

\section{Fonte dos dados}

As informações analisadas nesse trabalho foram extraídas dos relatórios de produção de pescado marítimo e estuarino do Estado de Pernambuco, publicados nos boletins do CEPENE referentes ao período de 1999 a 2006. Estes relatórios dizem respeito à atividade desenvolvida em um total de 15 das 21 comunidades existente no litoral. Os 15 municípios cujos dados foram sistematizados são: Goiana, Ilha de Itamaracá, Itapissuma, Igarassu, Abreu e Lima, Paulista, Olinda, Recife, Jaboatão dos Guararapes, Cabo de Santo Agostinho, Ipojuca, Sirinhaém, Rio Formoso, Tamandaré e o município de São José da Coroa Grande. Os dados disponíveis nesses boletins foram obtidos por amostragens baseadas no sistema de coleta do Programa ESTATPESCA, descrito em Ibama (1995) e analisado por Aragão et al. (2005).

\section{Estratificação e análise dos dados}

A análise estatística dos dados de pesca de Pernambuco foi estratificada por ano (entre 1999 e 2006), município (Goiana, Ilha de Itamaracá, Itapissuma, Igarassu, Abreu e Lima, Paulista, Olinda, Recife, Jaboatão dos Guararapes, Cabo de Santo Agostinho, Ipojuca, Sirinhaém, Rio Formoso, Tamandaré e o município de São José da Coroa Grande), tipo de embarcação (descritas na Tabela I), arte de pesca (descritas na Tabela 2) e categoria específica do pescado. As categorias de pescado consistem das listas apresentadas nos relatórios do IBAMA/CEPENE, e que descrevem os nomes vulgares e científicos das espécies.

As embarcações são classificadas em quatro categorias, como apresentado na Tabela 1.

Os meios de captura/arte de pesca e as categorias específicas do pescado seguiu a classificação apresentadas nos relatórios do IBAMA/CEPENE (2008). A Tabela 2 apresenta as categorias e suas respectivas descrições. 
Tabela 1 - Classificação das embarcações típicas do litoral de Pernambuco estudadas entre os anos de 1999 a 2006 (Ibama/ Cepene, 2008).

\begin{tabular}{ll}
\hline Categorias & Descrição \\
\hline Canoa & $\begin{array}{l}\text { Embarcação movida a remo, vela ou vara. Não possui convés, com comprimento variando } \\
\text { entre 3 e 7 metros, vulgarmente conhecida como baiteira. }\end{array}$ \\
Jangada & $\begin{array}{l}\text { Embarcação variando entre } 3 \text { e } 7 \text { metros de comprimento, com ou sem quilha, movidas a } \\
\text { vela, remo ou vara. }\end{array}$ \\
$\begin{array}{l}\text { Embarcações Motorizadas } \\
\text { (Pequena, Média e Grande) }\end{array}$ & $\begin{array}{l}\text { Também classificadas neste tipo as jangadas motorizadas. São confeccionados de madeira, } \\
\text { boletins não especificam a distinção em metros entre as categorias. }\end{array}$ \\
$\begin{array}{l}\text { Industrial } \\
\text { (Pequeno e Médio) }\end{array}$ & $\begin{array}{l}\text { Embarcação com comprimento entre 20 e 25 metros, utilizada na pesca em escala industrial e } \\
\text { de propriedade de empresas da indústria pesqueira. } \\
\text { Pescaria sem arte de pesca, que dispensa o uso de qualquer aparelho de pesca vulgarmente } \\
\text { Manual }\end{array}$ \\
\hline
\end{tabular}

Tabela 2 - Características gerais qualitativas dos meios de captura/arte de pesca do litoral de Pernambuco estudados entre os anos de 1999 a 2006 (Ibama/Cepene, 2008).

\begin{tabular}{|c|c|}
\hline Categorias & Descrição \\
\hline Arrasto de Praia & Utiliza-se uma rede com 150 a 200 metros de comprimento por 3 metros de altura. \\
\hline Bicheiro & Cabo feito de cano de plástico resistente ou ferro e ponteira de aço. \\
\hline Caçoeira & $\begin{array}{l}\text { Rede de espera de fios de nylon utilizada na captura de lagostas. Vulgarmente conhecida como: } \\
\text { Caçoeira para lagosta, rede de espera para lagosta, rede de lagosta. }\end{array}$ \\
\hline Compressor & $\begin{array}{l}\text { As embarcações utilizam um equipamento auxiliar de mergulho, denominado compressor de ar, } \\
\text { que é adaptado ao motor da embarcação. }\end{array}$ \\
\hline Covo de Peixe & $\begin{array}{l}\text { Armadilha de fundo, semi-fixa, de formato hexagonal e quadrangular, revestida com malha de } \\
\text { nylon. Possui uma entrada "sanga" e é vulgarmente conhecida como covo palheta, covo para peixe } \\
\text { ou viveiro. }\end{array}$ \\
\hline Curral & Armadilhas fixas construídos com varas e arames, implantados no solo. \\
\hline Espinhel & $\begin{array}{l}\text { Utilizado por embarcações atuneiras nacionais e arrendadas. Consiste de uma linha principal de } \\
3 \mathrm{~mm} \text { de diâmetro à qual estão ligadas linhas secundárias, variando de } 5 \text { a } 7 \text { linhas. }\end{array}$ \\
\hline Jereré para voador & Puçá utilizado na captura de peixe voador. \\
\hline Linha aratu & Linha de nylon usada manualmente com isca amarrada na ponta \\
\hline Linha de vara & Usadas manualmente pelo homem com o auxílio de vara. \\
\hline Linhas & As pescarias são realizadas com linhas de fundo ou de superfície. \\
\hline Mangote & $\begin{array}{l}\text { Redes de arrasto com comprimento em torno de } 180 \mathrm{~m} \text {, geralmente utilizadas na praia, canais e } \\
\text { enseadas, puxadas por um ou dois homens. Vulgarmente conhecidas como: Mangote, redinha, } \\
\text { andarilho e pesca de calão. }\end{array}$ \\
\hline Mangote do alto & Rede de arrasto, geralmente utilizadas em canais, enseadas e praias. \\
\hline Manual & $\begin{array}{l}\text { Pescarias sem arte de pesca, que dispensam o uso de qualquer aparelho, podendo no máximo } \\
\text { utilizar algumas ferramentas, tais como: Foice, estilete, varão, fisgas etc. }\end{array}$ \\
\hline Manzuá & Engradado de varas, parecido com covo de peixe. \\
\hline Mergulho Livre & $\begin{array}{l}\text { Pescarias realizadas com bicheiro, espingarda de pressão ou ar-balete e utensílios esportivos de } \\
\text { mergulho, para captura de lagostas, polvo e peixes. }\end{array}$ \\
\hline Mistas & Quando usados dois petrechos em uma mesma pescaria. \\
\hline Rede de Arrasto & Redes de arrasto de fundo de fios de nylon com comprimento variável. \\
\hline Rede de Cerco & Redes que têm o objetivo de cercar o cardume. \\
\hline Rede de Espera & $\begin{array}{l}\text { Nesta categoria estão incluídos os tipos de redes que ficam verticalmente na coluna d'água, onde o } \\
\text { peixe é emalhado, podendo ser de deriva, quando opera ao sabor das correntes, ou fixa, presas ao } \\
\text { substrato por meio de fateixas. }\end{array}$ \\
\hline Sauneira & Rede de emalhar com linha mais fina e malhar menor. \\
\hline Tainheira & $\begin{array}{l}\text { Tipo de rede de emalhar utilizada, principalmente, em estuários de Pernambuco, em profundidade } \\
\text { que não alcança } 5 \text { metros. }\end{array}$ \\
\hline Tarrafa & Redes de cobrir que se abrem quando lançadas, capturam os peixes caindo e fechando sobre eles. \\
\hline
\end{tabular}

As análises descritivas dos dados foram realizadas com base em medidas de tendência central (e.g., médias, medianas, quartis), e para a identificação de padrões e tendên- 
cias dos dados foram usados gráficos (e.g., gráficos de barras e diagramas de caixas) e tabelas. No parágrafo de crescimentos anuais $(T x)$ que correspondem ao crescimento ou decrescimento dos desembarques de um ano para o outro foi calculada pela equação: $T x=(100 \times B / A)-100$; onde $B$ é o ano posterior e $A$ corresponde ao ano anterior.

Inferências estatísticas foram realizadas para avaliar possíveis diferenças significativas $(\alpha=0,05)$ entre os desembarques anuais, municípios, embarcações e Famílias de espécies. Inicialmente foram realizados testes para avaliar as hipóteses de normalidade e homocedasticidade dos dados, as quais foram rejeitadas, e assim procedeu-se com o uso de testes não paramétricas, para os quais foram utilizados os de Kruskal-Wallis (Kruskal \& Wallis, 1952).

A Captura por Unidade de Esforço $(U)$ foi estimada para cada município pela fórmula: $U=C / f$; em que $C$ é o desembarque em peso (em toneladas) em determinado ano e $f$ é o esforço expresso em número de embarcações atuantes no mesmo ano, sendo $U$ expresso em tonelada/embarcação.ano.

Os dados disponíveis não permitiram analisar a captura por tipo de arte de pesca, portanto, a captura por unidade de esforço $(U)$ reflete a modalidade de pesca predominante em Pernambuco - pesca artesanal - que se caracteriza pela multiespecificidade de espécies e arte de pesca (Lessa et al., 2006; 2011).

Por fim, analises de agrupamentos foram utilizadas para distinguir os municípios quanto ao tipo das pescarias (e.g. tipo e tamanho de embarcação, espécie mais capturada). Os cálculos foram baseados em distâncias euclidianas, por ser de fácil compreensão, não apresentar limite superior e possibilitar a consideração de duplas-ausências. Os dados não foram padronizados, pois o objetivo não foi comparar os resultados obtidos com outras medidas de similaridade. Os resultados finais foram apresentados na forma de dendrograma. Detalhes sobre análises multivariadas podem ser encontrados em livros texto como o de Manly (2005).

As análises dos dados foram realizadas com o programa R (R CORE TEAM, 2017).

\section{RESULTADOS}

Nesta seção são apresentados, em sequência de tópicos, os desembarques anuais e por município, desembarques nas artes e embarcações por municípios, desembarques anuais das espécies nos municípios e análise de agrupamento por município.

\section{Desembarques anuais e por município}

Entre os anos de 1999 e 2006, ficou evidente a tendência de crescimento dos desembarques a partir de 2004. Verificou-se diferença estatística nos desembarques anuais, quando submetidos ao teste de Kruskal-Wallis $\left(p=2,54 \times 10^{-15}\right)$ (Figura $\left.1 \mathrm{~A}\right)$. Os desembarques nos anos de 2005 e 2006 foram significativamente distintos que os dos demais.

Os desembarques médios anuais dos 15 municípios também mostraram diferenças significativas $\left(p=1,79 \times 10^{-10}\right)$ nos desembarques médios anuais (Figura $1 \mathrm{~B}$ ). Dentre os municípios avaliados, Itapissuma e Goiana tiveram medianas de desembarques anuais significativamente mais elevadas no período. 


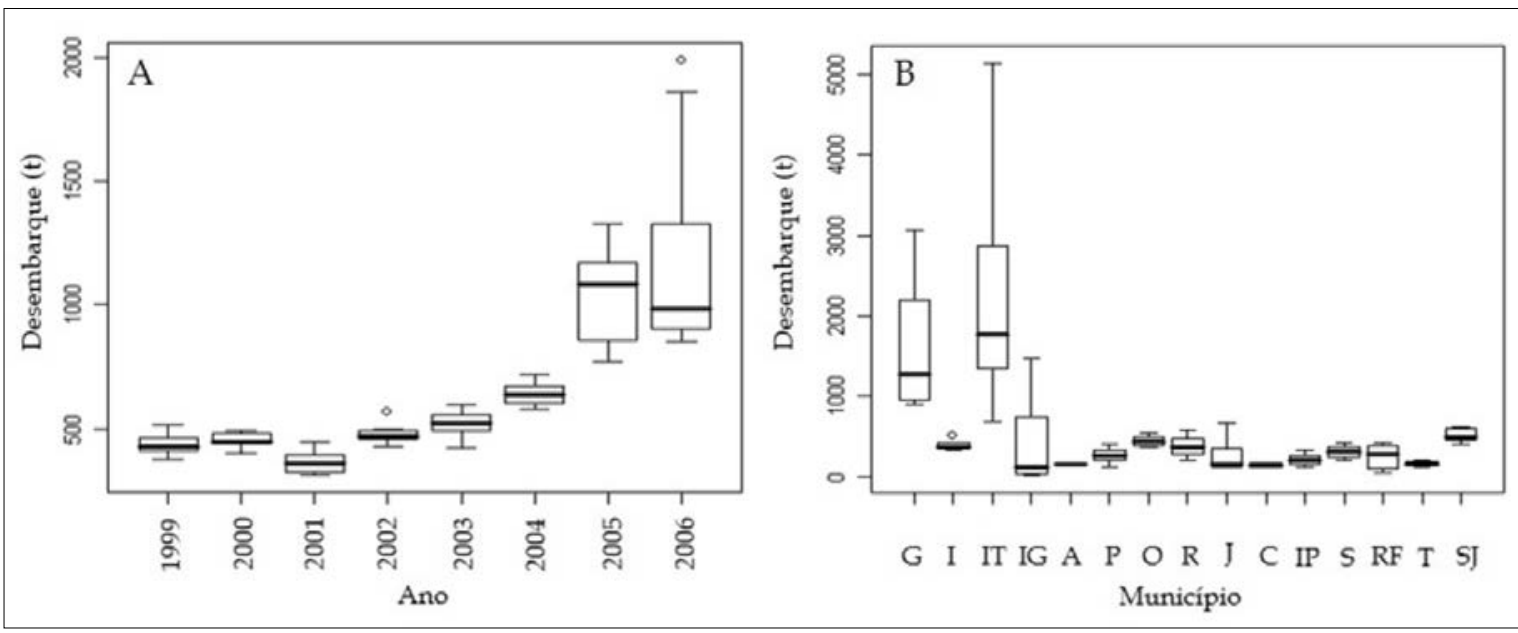

Figura 1 - Desembarques mensais agrupados por ano (A) e desembarques anuais por município (B). No painel B, as representações dos municípios ordenados do litoral norte para o sul são: G - Goiana; I - Itamaracá; IT - Itapissuma; IG - Igarassu; A - Abreu e Lima; P - Paulista; O - Olinda; R - Recife; J - Jaboatão dos Guararapes; C - Cabo de Santo Agostinho; IP Ipojuca; S - Sirinhaém; RF - RF - Rio Formoso; T - Tamandaré; e SJ - São José da Coroa Grande.

As taxas de crescimento de um ano para outro nos desembarques dos municípios estão dispostas na Tabela 3. Em seis municípios (Goiana, Igarassu, Jaboatão dos Guararapes, Cabo de Santo Agostinho, Ipojuca e Tamandaré), a maior taxa de crescimento ocorreu de 2004 para 2005. Valores negativos de crescimento ocorreram para a maioria dos municípios, exceto Igarassu, que apresentou valores positivos nos períodos 1999-2000, e 2000-2001. Para o município de Abreu e Lima somente foi calculada a taxa de crescimento de 2005 para 2006 que corresponde ao período em que os dados estavam disponíveis para o município.

Tabela 3 - Percentual de crescimento dos desembarques dos municípios em relação ao ano de 2004. As representações dos municípios ordenados do litoral norte para o sul são: G - Goiana; I - Itamaracá; IT - Itapissuma; IG - Igarassu; A - Abreu e Lima; P - Paulista; O - Olinda; R - Recife; J - Jaboatão dos Guararapes; C - Cabo de Santo Agostinho; IP - Ipojuca; S Sirinhaém; RF - RF - Rio Formoso; T - Tamandaré; e SJ - São José da Coroa Grande.

\begin{tabular}{|c|c|c|c|c|c|c|c|c|c|c|c|c|c|c|c|}
\hline Período & G & I & IT & IG & A & $\mathrm{P}$ & $\mathrm{O}$ & $\mathrm{R}$ & $\mathrm{J}$ & $\mathrm{C}$ & IP & $\mathrm{S}$ & RF & $\mathrm{T}$ & SJ \\
\hline $1999-2000$ & 39,9 & $-38,3$ & 45,9 & 195,7 & & 151,3 & $-7,6$ & $-6,3$ & 1,7 & 10,4 & $-18,2$ & 18,8 & $-34,5$ & 22,4 & 50,3 \\
\hline $2000-2001$ & $-30,7$ & $-35,3$ & $-32,4$ & 64,2 & & $-0,8$ & $-4,2$ & $-22,6$ & $-10,0$ & $-16,4$ & 90,4 & $-2,5$ & 191,5 & $-32,8$ & $-24,2$ \\
\hline $2001-2002$ & 5,9 & 156,7 & 20,7 & 167,2 & & $-34,1$ & $-3,6$ & 76,5 & 6,1 & $-15,8$ & 4,6 & 29,8 & 81,9 & 21,1 & 1,0 \\
\hline $2002-2003$ & 28,4 & $-9,8$ & $-21,7$ & 110,6 & & 31,6 & $-14,1$ & $-3,0$ & 40,3 & 13,5 & $-19,2$ & 5,3 & 44,4 & 35,0 & 3,5 \\
\hline 2003-2004 & 25,2 & 44,9 & 17,3 & $-14,8$ & & 2,6 & $-4,7$ & $-4,8$ & 6,8 & $-15,2$ & $-14,1$ & $-0,3$ & 5,8 & $-17,4$ & 2,9 \\
\hline 2004-2005 & 99,3 & 45,8 & $-8,2$ & 811,6 & & 66,8 & 4,8 & 66,8 & 190,1 & 55,2 & 108,3 & 25,5 & 21,6 & 40,5 & 26,7 \\
\hline 2005-2006 & $-6,7$ & 51,4 & 15,8 & $-12,3$ & 10,0 & $-6,6$ & 7,2 & $-1,6$ & 29,3 & $-4,0$ & $-12,8$ & $-1,3$ & $-6,1$ & $-4,3$ & $-3,4$ \\
\hline
\end{tabular}

\section{Artes de pesca por município}

As artes de pesca utilizadas no litoral de Pernambuco são variadas, até mesmo entre os municípios. A rede de espera foi o único meio de captura presente em todos os municípios com destaque para as médias de capturas anuais em Itapissuma e Goiana. O covo para peixe, linhas, caçoeira, rede de cerco, tarrafa e coleta manual foram também modalidades bastante empregadas (Tabela 4).

Os municípios que apresentaram uma diversidade maior de artes de pesca foram os de Goiana e São José da Coroa Grande, tendo sido registradas 19 das 28 artes descritas. Os 
municípios de Cabo de Santo Agostinho, Itamaracá, Sirinhaém e Tamandaré também se destacaram pela elevada variedade das modalidades de captura utilizadas (Tabela 4).

As principais artes de pesca utilizadas nas capturas por município e respectivas médias anuais foram: linhas em Recife (108,5 t.ano $\left.{ }^{-1}\right)$; Jaboatão dos Guararapes (103,8 t.ano $\left.{ }^{-1}\right)$; Cabo de Santo Agostinho (53,5 t.ano $\left.{ }^{-1}\right)$; Ipojuca (65,3 t.ano $\left.{ }^{-1}\right)$; Tamandaré (51,8 t.ano $\left.{ }^{-1}\right)$ e São José da Coroa Grande (179,5 t.ano $\left.{ }^{-1}\right)$; coleta manual em Goiana (596,8 t.ano ${ }^{-1}$ ); Igarassu $\left(420,0\right.$ t.ano $\left.^{-1}\right)$ e Rio Formoso $\left(93,7\right.$ t.ano $\left.^{-1}\right)$; covo de peixe em Itamaracá $\left(247,1\right.$ t.ano $\left.{ }^{-1}\right)$; Paulista $\left(117,1\right.$ t.ano $\left.{ }^{-1}\right)$ e Olinda $\left(189,2\right.$ t.ano $\left.^{-1}\right)$; rede de espera em Abreu e Lima (59,0 t.ano $\left.{ }^{-1}\right)$ e Sirinhaém (122,0 t.ano $\left.{ }^{-1}\right)$; e mangote em Itapissuma $\left(839,0\right.$ t.ano $\left.{ }^{-1}\right)$.

Tabela 4 - Médias das capturas anuais das artes de pesca utilizadas nos 15 municípios avaliados do litoral de Pernambuco.

\begin{tabular}{|c|c|c|c|c|c|c|c|c|c|c|c|c|c|c|c|}
\hline Arte de pesca & $\begin{array}{l}\text { Oి. } \\
\text { : } \\
\text { : }\end{array}$ & 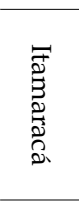 & 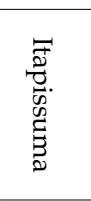 & 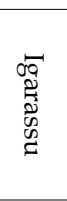 & $\begin{array}{l}\mathbb{D} \\
0 \\
0 \\
0 \\
0 \\
D \\
5 \\
0 \\
0\end{array}$ & 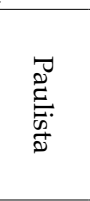 & $\frac{O}{5}$ & 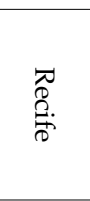 & 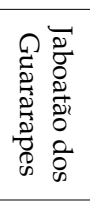 & 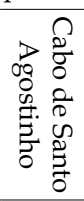 & $\frac{\vec{\nabla}}{\stackrel{D}{0} .}$ & 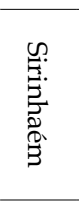 & $\begin{array}{l}7 \\
0 \\
0 \\
T \\
0 \\
0 \\
0 \\
0 \\
0\end{array}$ & 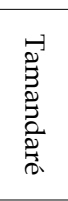 & 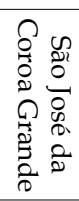 \\
\hline $\begin{array}{l}\text { Arrastão de } \\
\text { Praia }\end{array}$ & 0,0 & 0,0 & 0,0 & 0,0 & 0,0 & 0,7 & 0,7 & 0,0 & 0,0 & 0,0 & 1,2 & 3,8 & 0,0 & 0,5 & 16,4 \\
\hline Bicheiro & 0,0 & 0,0 & 0,0 & 0,0 & 0,0 & 0,0 & 0,0 & 0,0 & 0,0 & 0,0 & 0,0 & 0,0 & 0,0 & 0,1 & 0,0 \\
\hline Caçoeria & 7,3 & 2,3 & 0,0 & 0,0 & 0,0 & 4,9 & 3,5 & 31,6 & 3,8 & 5,4 & 18,7 & 34,3 & 0,0 & 8,5 & 53,7 \\
\hline Caçoeria/ linha & 0,0 & 0,0 & 0,0 & 0,0 & 0,0 & 0,0 & 0,0 & 0,3 & 1,2 & 0,0 & 0,0 & 2,8 & 0,0 & 0,0 & 29,7 \\
\hline Compressor & 7,0 & 0,0 & 0,0 & 0,0 & 0,0 & 0,8 & 0,0 & 21,4 & 1,6 & 2,9 & 0,0 & 0,1 & 0,0 & 1,3 & 5,4 \\
\hline $\begin{array}{l}\text { Compressor } \\
\text { peixe/lagosta }\end{array}$ & 0,0 & 0,0 & 0,0 & 0,0 & 0,0 & 0,0 & 0,0 & 3,8 & 53,7 & 0,0 & 0,0 & 0,0 & 0,0 & 0,0 & 1,6 \\
\hline Covo peixe & 395,3 & 247,1 & 0,0 & 0,0 & 0,0 & 117,7 & 149,7 & 37,4 & 43,9 & 35,3 & 1,7 & 3,3 & 0,0 & 0,1 & 4,5 \\
\hline $\begin{array}{l}\text { Covo peixe/ } \\
\text { linha }\end{array}$ & 0,0 & 5,1 & 0,0 & 0,0 & 0,0 & 0,0 & 0,0 & 0,0 & 0,0 & 0,1 & 0,0 & 0,0 & 0,0 & 0,0 & 0,0 \\
\hline $\begin{array}{l}\text { Covo peixe/ } \\
\text { manzuá }\end{array}$ & 0,0 & 12,0 & 0,0 & 0,0 & 0,0 & 0,0 & 0,0 & 0,0 & 0,0 & 0,0 & 0,0 & 0,0 & 0,0 & 0,0 & 0,0 \\
\hline $\begin{array}{l}\text { covo peixe/rede } \\
\text { de espera }\end{array}$ & 0,0 & 12,0 & 0,0 & 0,0 & 0,0 & 0,0 & 0,0 & 0,0 & 0,0 & 0,1 & 0,0 & 0,0 & 0,0 & 0,0 & 0,0 \\
\hline Curral & 94,4 & 46,1 & 10,5 & 0,0 & 0,0 & 0,0 & 0,0 & 0,0 & 0,3 & 0,0 & 0,0 & 2,4 & 0,8 & 0,6 & 0 \\
\hline Espinhel & 0,0 & 0,0 & 0,0 & 0,0 & 0,0 & 0,0 & 0,0 & 3,8 & 0,0 & 0,2 & 0,0 & 0,0 & 0,0 & 0,4 & 2,8 \\
\hline $\begin{array}{l}\text { Jereré para } \\
\text { voador }\end{array}$ & 0,0 & 0,0 & 0,0 & 0,0 & 0,0 & 0,0 & 0,0 & 0,0 & 0,0 & 0,0 & 0,0 & 0,0 & 0,0 & 0,0 & 0,0 \\
\hline Linha aratu & 0,3 & 0,0 & 0,0 & 0,0 & 0,0 & 0,0 & 0,0 & 0,0 & 0,0 & 0,0 & 0,0 & 1,2 & 0,5 & 0,0 & 0,1 \\
\hline Linha de vara & 0,3 & 0,0 & 254,6 & 17,1 & 0,0 & 0,0 & 0,0 & 0,0 & 0,0 & 0,2 & 0,0 & 8,6 & 9,3 & 0,1 & 0,2 \\
\hline Linhas & 16,3 & 28,1 & 15,1 & 1,7 & 0,0 & 37,6 & 189,2 & 108,5 & 103,8 & 27,9 & 65,3 & 34,6 & 13,5 & 51,8 & 179,5 \\
\hline Mangote & 222,4 & 4,5 & 839 & 0,0 & 43,4 & 0,0 & 39,0 & 0,0 & 0,0 & 4,1 & 0,0 & 0,0 & 28,4 & 0,6 & 1,2 \\
\hline Mangote do alto & 7,2 & 0,0 & 0,0 & 0,0 & 0,0 & 0,0 & 0,0 & 0,0 & 0,0 & 0,0 & 0,0 & 0,0 & 0,0 & 0,0 & 0,0 \\
\hline Manual & 596,8 & 0,0 & 764,7 & 420 & 49,4 & 0,0 & 0,5 & 3,3 & 0,0 & 0,8 & 0,0 & 17,6 & 93,7 & 1,8 & 36,5 \\
\hline Manzuá & 0,3 & 0,0 & 0,0 & 0,0 & 0,0 & 0,0 & 1,5 & 2,5 & 2,1 & 1,2 & 0,0 & 0,0 & 0,0 & 0,0 & 0,0 \\
\hline Mergulho livre & 9,6 & 3,2 & 0,0 & 0,0 & 0,0 & 0,0 & 0,0 & 0,0 & 0,6 & 0,1 & 0,8 & 0,5 & 0,0 & 1,9 & 0,0 \\
\hline Rede de arrasto & 0,0 & 0,0 & 0,0 & 0,0 & 0,0 & 0,9 & 0,1 & 20,8 & 6,7 & 4,0 & 20,7 & 74,9 & 0,0 & 31,2 & 42,7 \\
\hline Rede de cerco & 23,5 & 9,1 & 0,0 & 0,6 & 0,0 & 4,8 & 2,3 & 78,9 & 9,1 & 5,4 & 38,5 & 4,1 & 0,0 & 9,8 & 14,4 \\
\hline Rede de espera & 187 & 28 & 458,4 & 29,1 & 59,0 & 97,3 & 58,0 & 67,8 & 27,7 & 53,5 & 61,4 & 122 & 88,8 & 50 & 122 \\
\hline $\begin{array}{l}\text { Rede de espera/ } \\
\text { caçoeira }\end{array}$ & 0,6 & 0,0 & 0,0 & 0,0 & 0,0 & 0,0 & 0,0 & 0,0 & 0,0 & 0,0 & 0,0 & 0,0 & 0,0 & 0,0 & 0,0 \\
\hline Sauneira & 1,1 & 0,1 & 5,8 & 0,0 & 0,0 & 0,0 & 0,0 & 0,0 & 0,0 & 0,0 & 0,0 & 0,1 & 0,3 & 0,0 & 0,2 \\
\hline Tanheira & 1,9 & 0,2 & 3,3 & 0,0 & 0,0 & 0,0 & 0,0 & 0,0 & 0,0 & 0,0 & 0,0 & 0,3 & 0,2 & 0,4 & 1,5 \\
\hline Tarrafa & 0,1 & 0,0 & 0,0 & 0,0 & 0,0 & 0,2 & 0,7 & 0,2 & 0,2 & 1,2 & 2,3 & 2,3 & 13,1 & 6,3 & 3,6 \\
\hline
\end{tabular}


Entre as 28 artes de pesca registradas, as modalidades que apresentaram os maiores desembarques anuais foram, em ordem decrescente: (i) Manual, (ii) Rede de espera, (ii) Mangote, (iv) Covo de peixe e (v) Linhas.

A coleta manual apresentou um aumento acentuado na captura, nos anos de $2005 \mathrm{e}$ 2006, nos municípios de Goiana, Itapissuma e Igarassu (Figura 2 A, B e C). As pescarias com rede de espera apresentaram ligeiro aumento em 2005 e 2006 nos municípios de Jaboatão dos Guararapes, Rio Formoso, Tamandaré e São José da Coroa Grande (Figura 2 I, L, M, N), ocorrendo o mesmo para os desembarques com linhas em Jaboatão dos Guararapes e Ipojuca (Figura 2 I e K).

Nos municípios de Olinda e Cabo de Santo Agostinho ocorreram declínios dos desebarques com linhas (Figura $2 \mathrm{G}$ e J). As astes de pesca registradas nos municípios de Itamaracá, Paulista, Recife e São José da Coroa Grande (Figura 2 B, F, H e O) não tiveram elevados acréscimo ou decréscimo no período. No município de Abreu e Lima (Figura 2 E) só existem dados de dois anos (2005 e 2006) com desembarque de somente três modalidades de pesca.

Em geral, a produção da captura pernambucana por meio da coleta manual apresenta diferenças significativas quando comparada aos demais meios de captura, com exceção da rede de espera (Figura 2 P).

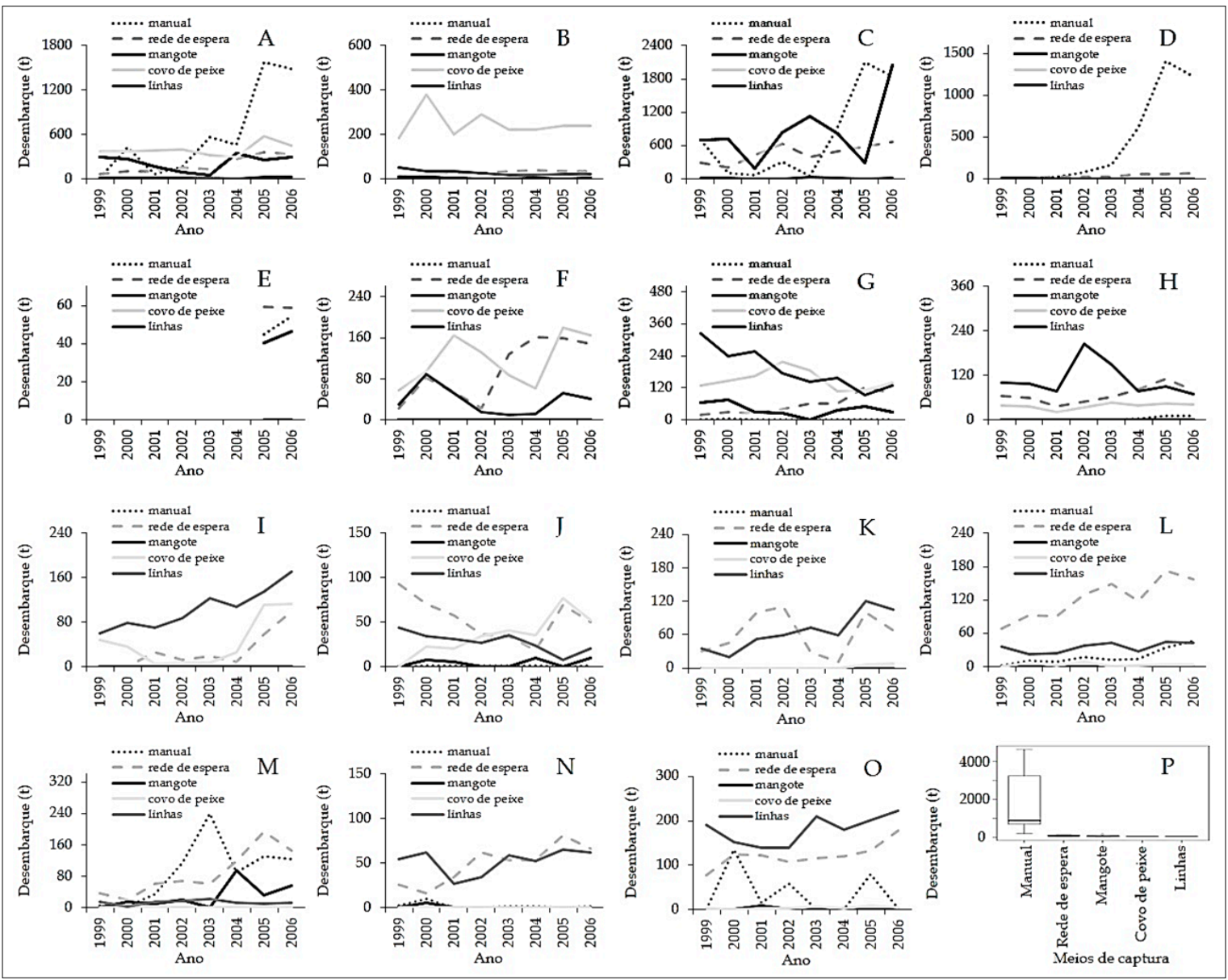

Figura 2 - Variação temporal dos desembarques das cinco principais arte de pesca utilizadas em Pernambuco por município: Goiana (A), Itamaracá (B), Itapissuma (C), Igarassu (D), Abreu e Lima (E), Paulista (F), Olinda (G), Recife (H), Jaboatão dos Guararapes (I), Cabo de Santo Agostinho (J), Ipojuca (K), Sirinhaém (L), Rio Formoso (M) Tamandaré (N) e São José da Coroa Grande $(\mathrm{O})$ e Diagramas de caixas com as representações da mediana, dos quartis e de valores extremos incluindo discrepantes (círculos abertos) dos desembarques anuais das cinco principais artes de pesca utilizadas no Estado de Pernambuco (P). 


\section{Embarcações por município}

As principais modalidades utilizadas no desembarque das espécies capturadas em cada município e respectivas médias anuais foram: embarcações motorizadas de médio porte em Itamaracá (253,8 t.ano $\left.{ }^{-1}\right)$; Recife $\left(195,7\right.$ t.ano $\left.^{-1}\right)$; Jaboatão $\left(152,9\right.$ t.ano $\left.{ }^{-1}\right)$; Cabo $(61,3$ t.ano $\left.{ }^{-1}\right)$; Ipojuca (106,9 t.ano $\left.{ }^{-1}\right)$; Sirinhaém $\left(209,2\right.$ t.ano $\left.{ }^{-1}\right)$; Tamandaré $\left(89,4\right.$ t.ano $\left.^{-1}\right)$ e São José $\left(269,0\right.$ t.ano $\left.{ }^{-1}\right)$; Canoa em Goiana (701,2 t.ano $\left.{ }^{-1}\right)$; Itapissuma (1.571,7 t.ano $\left.{ }^{-1}\right)$; Abreu e Lima $\left(151,9\right.$ t.ano $\left.{ }^{-1}\right)$ e Rio Formoso $\left(154,0\right.$ t.ano $\left.{ }^{-1}\right)$; embarcações motorizadas de pequeno porte em Paulista $\left(110,7\right.$ t.ano $\left.{ }^{-1}\right)$ e Olinda $\left(183,6\right.$ t.ano $\left.^{-1}\right)$ e deslocamento predominante terrestre com coleta manual em Igarassu $\left(499,5\right.$ t.ano $\left.{ }^{-1}\right)$.

A produção apresentou maior variabilidade quando a captura foi realizada com o uso de canoas (Figura 3 P). Esta categoria apresentou um valor de captura discrepante da ordem de 5.451,3 t referente à captura do ano de 2006. Os desembarques anuais obtidos pelos diversos tipos de embarcações apresentaram diferença estatística $\left(p=3,31 \times 10^{-8}\right)$.

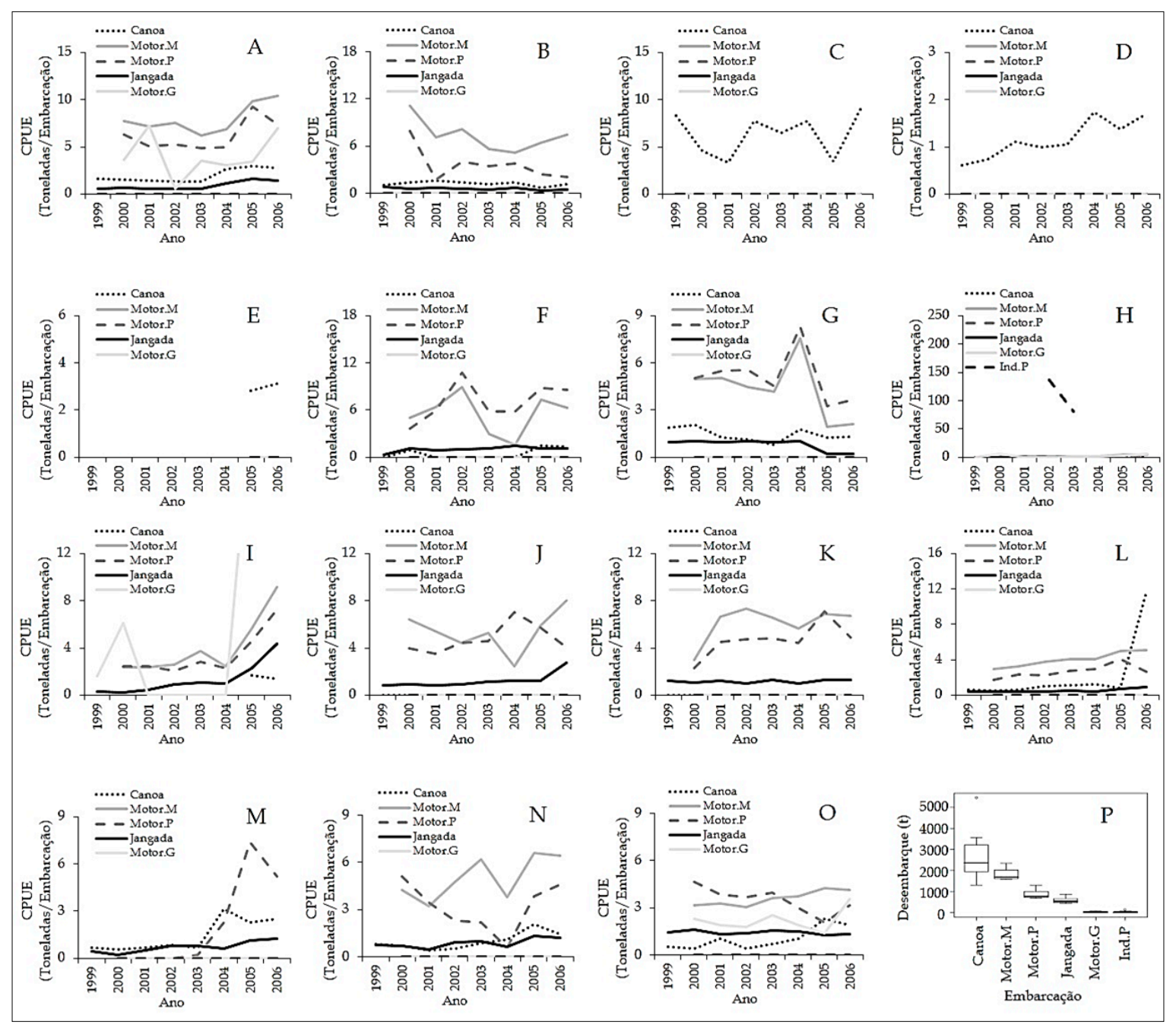

Figura 3 - Variação temporal dos desembarques dos meios de deslocamentos utilizados em diferentes municípios de Pernambuco: Goiana (A), Itamaracá (B), Itapissuma (C), Igarassu (D), Abreu e Lima (E), Paulista (F), Olinda (G), Recife (H), Jaboatão dos Guararapes (I), Cabo de Santo Agostinho (J), Ipojuca (K), Sirinhaém (L), Rio Formoso (M) Tamandaré (N) e São José da Coroa Grande $(\mathrm{O})$ e $(\mathrm{P})$. Desembarques anuais por modalidade de deslocamento utilizada na operação de pesca. No painel P, termos: Motor.M - embarcação motorizada de médio porte; Motor.P - embarcação motorizada de pequeno porte; Motor.G - embarcação motorizada de grande porte; Ind.P - Industrial de pequeno porte. 
Os desembarques anuais obtidos com canoas e embarcações motorizadas de médio porte foram diferentes estatisticamente das capturas obtidas com embarcações motorizadas grandes e industriais pequenas.

\section{Desembarques anuais das espécies nos municípios}

O desembarque de peixes no período avaliado foi sistematicamente superior aos de moluscos e crustáceos (Figura 4 A). Os três grupos (peixes, moluscos e crustáceos) tiveram aumentos das capturas especialmente em 2005 e 2006, porém, para os moluscos, as capturas foram substancialmente maiores.

Em praticamente todos os municípios, a categoria dos peixes apresentou maior contribuição percentual (Figura 4 B), com exceção de Igarassu, onde a maior parte das capturas (58\%) era composta de moluscos. Além de Igarassu, outros municípios se destacaram na captura de moluscos, como Goiana, Itapissuma, Abreu e Lima e Rio Formoso, com contribuições de 35\%,29\%, 36\% e 31\%, respectivamente. Já os crustáceos tiveram as maiores capturas nos municípios de Sirinhaém (37\%), Tamandaré (22\%) e São José da Coroa Grande (21\%).

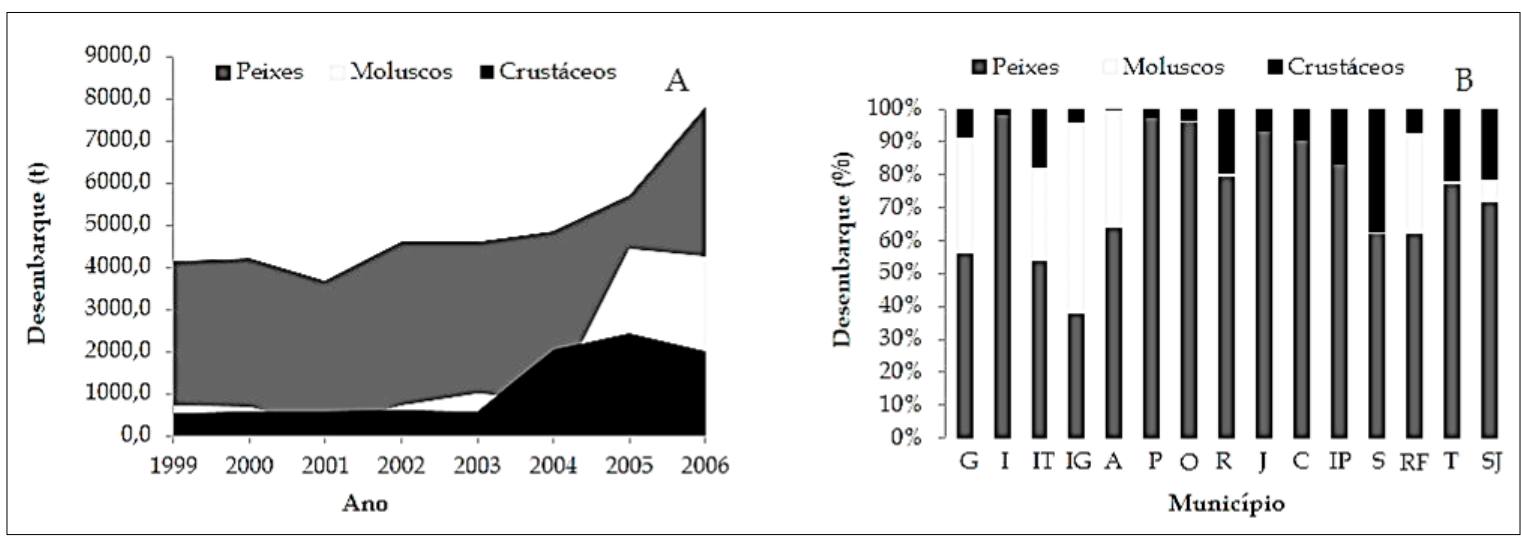

Figura 4 - (A) Produções anuais das categorias de pescado; (B) Contribuição percentual das categorias de pescado para os totais desembarcados por município ao considerar os todos os dados agrupados. Representações dos municípios são: $G$ Goiana; I - Itamaracá; IT - Itapissuma; IG - Igarassu; A - Abreu e Lima; P - Paulista; O - Olinda; R - Recife; J - Jaboatão dos Guararapes; C - Cabo de Santo Agostinho; IP - Ipojuca; S - Sirinhaém; RF - RF - Rio Formoso; T - Tamandaré; e SJ - São José da Coroa Grande.

Na pescaria de Pernambuco, 15 Famílias de pescado tiveram grande destaque em termos de quantidade capturada, sendo que nove delas pertenciam ao grupo dos Peixes (Engraulidae, Mugilidae, Haemulidae, Mullidae, Carangidae, Lutjanidae, Scaridae, Scombridae e Clupeidae), três ao grupo dos Moluscos (Veneridae, Ostreidae e Mytilidae) e três ao grupo dos Crustáceos (Penaeidae, Portunidae e Polinuridae) (Tabela 5). O aumento observado do desembarque nos anos de 2005 e 2006 ocorreu para a maioria das famílias, porém com destaque para as Famílias Veneridae, Ostreidae, Portunidae, Mytilidae, e Engraulidae, sendo que as quatro primeiras citadas foram capturadas predominantemente por coleta manual.

As capturas das diversas famílias ao longo dos anos apresentaram diferenças significativas $\left(p=8,68 \times 10^{-3}\right)$. De maneira geral, as diferenças foram significativas entre as famílias Veneridae, Engraulidae, Mugilidae, Haemulidae e Mullidae que tiveram maiores desembarques em relação à Portunidae, Mytilidae, Scaridae, Palinuridae, Scombridae e Clupeidae, por serem estas as capturadas em menor quantidade. 
Tabela 5 - Desembarques de famílias de peixes, moluscos e crustáceos, por ano. CV - Coeficiente de variação.

\begin{tabular}{lccccccccccc}
\hline Família & Grupo & 1999 & 2000 & 2001 & 2002 & 2003 & 2004 & 2005 & 2006 & Média & CV \\
\hline Veneridae & Molusco & 0,1 & 581,8 & 90,5 & 70,1 & 820,1 & 1159,2 & 2478,1 & 2475,3 & 959,4 & 1,0 \\
Engraulidae & Peixe & 351,8 & 370,1 & 326,1 & 751,9 & 931,0 & 588,2 & 70,1 & 1754,9 & 643,0 & 0,8 \\
Mugilidae & Peixe & 289,8 & 254,1 & 370,3 & 459,8 & 412,5 & 591,5 & 986,9 & 890,0 & 531,9 & 0,5 \\
Haemulidae & Peixe & 425.6 & 397.4 & 464 & 370.9 & 417.3 & 455,0 & 568.2 & 599.4 & 462.2 & 0,2 \\
Mullidae & Peixe & 405,1 & 626,2 & 299 & 493,8 & 362,6 & 309,8 & 522,7 & 433,3 & 431,6 & 0,2 \\
Ostreidae & Molusco & 698,6 & 42,5 & 7,4 & 10,6 & 95,8 & 497,5 & 987,9 & 925,1 & 408,2 & 1,0 \\
Carangidae & Peixe & 492,9 & 376,0 & 413,0 & 278,3 & 344,2 & 292,2 & 429,4 & 368,0 & 374,3 & 0,2 \\
Lutjanidae & Peixe & 241,6 & 230,5 & 310,4 & 372,5 & 366,1 & 307,9 & 480,0 & 529,8 & 354,9 & 0,3 \\
Penaeidae & Crustáceo & 296,0 & 288,8 & 302,1 & 300,8 & 150,1 & 381,9 & 583,1 & 489,4 & 349,0 & 0,4 \\
Portunidae & Crustáceo & 1,2 & 18,6 & 7,7 & 11,6 & 48,1 & 121,8 & 1284,1 & 944,7 & 304,7 & 1,6 \\
Mytilidae & Molusco & 0,5 & 44,4 & 80,9 & 15,3 & 80,0 & 379,9 & 940,6 & 829,3 & 296,4 & 1,2 \\
Scaridae & Peixe & 323,6 & 401,5 & 162,1 & 136,5 & 139,4 & 363,3 & 280,7 & 356,5 & 270,5 & 0,4 \\
Palinuridae & Crustáceo & 197,6 & 245,9 & 221,5 & 224,3 & 185,4 & 265,3 & 304,8 & 351,9 & 249,6 & 0,2 \\
Scombridae & Peixe & 189,9 & 237,3 & 247,1 & 230,4 & 272,2 & 155,1 & 270,7 & 315,2 & 239,7 & 0,2 \\
Clupeidae & Peixe & 48,4 & 15,5 & 53,1 & 72,8 & 74,8 & 132,3 & 550,0 & 478,7 & 178,0 & 1,1 \\
\hline
\end{tabular}

Variações foram observadas nos desembarques para determinadas categorias de espécies (Tabela 6). Nos oito anos estudados, manjuba e camarões foram as espécies que apareceram com maior frequência entre as espécies com maiores quantidades de desembarque. A manjuba deixou de ser destaque apenas no ano de 2000, e os camarões, em 2006. Vale destacar também a tendência de incremento em importância da categoria marisco, que apareceu na primeira posição nos três últimos anos avaliados.

Tabela 6 - Cinco principais categorias específicas desembarcadas no decorrer dos anos estudados e seus respectivos desembarques totais. Os numerais que aparecem após o termo "categoria" indicam a posição na ordem de importância. $\mathrm{D}(\mathrm{t})$ Desembarque em toneladas. Categorias: Budião - Sparisoma spp.; Camarões - Penaiedae; Lagosta - Panulirus argus, Panulirus laevicauda e Scyllarides brasiliensis; Manjuba - Anchoa spp, Centengraulis edentulus, Anchoviella spp e Lycengraulis grossidens; Marisco - Anomalocardia flexuosa, Ostra - Crassostrea spp.; Sapuruna - Haemulidae; Saramunete - Pseudupeneus maculatus, Siri - Callinectes spp.; Sururu - Mytilus falcata; e Tainha - Mugil spp.

\begin{tabular}{lllllllllll}
\hline Ano & Espécie 1 & $\mathrm{D}(\mathrm{t})$ & Espécie 2 & $\mathrm{D}(\mathrm{t})$ & Espécie 3 & $\mathrm{D}(\mathrm{t})$ & Espécie 4 & $\mathrm{D}(\mathrm{t})$ & Espécie 5 & $\mathrm{D}(\mathrm{t})$ \\
\hline 1999 & Ostra & 698,6 & Saramunete & 405,1 & Manjuba & 351,8 & Budião & 323,6 & Camarões & 296,0 \\
2000 & Saramunete & 626,2 & Marisco & 581,8 & Budião & 401,5 & Manjuba & 370,1 & Camarões & 288,8 \\
2001 & Manjuba & 326,1 & Sapuruna & 312,6 & Camarões & 302,1 & Saramunete & 299,0 & Lagosta & 231,7 \\
2002 & Manjuba & 751,9 & Saramunete & 493,8 & Camarões & 300,8 & Sapuruna & 300,5 & Tainha & 270,3 \\
2003 & Manjuba & 931,0 & Marisco & 820,1 & Saramunete & 362,6 & Camarões & 278,6 & Sapuruna & 238,6 \\
2004 & Marisco & 1159,2 & Tainha & 591,5 & Manjuba & 588,2 & Ostra & 497,5 & Camarões & 381,9 \\
2005 & Marisco & 2478,1 & Siri & 1284,1 & Ostra & 987,9 & Sururu & 940,6 & Camarões & 583,1 \\
2006 & Marisco & 2475,3 & Manjuba & 1754,9 & Siri & 944,7 & Ostra & 925,1 & Sururu & 829,3 \\
\hline
\end{tabular}

\section{Análise de agrupamento por município}

As variáveis utilizadas na análise de agrupamento para a formação dos grupos de municípios foram: (i) meio de transporte mais utilizado na operação de pesca; (ii) grupo geral (peixes, moluscos ou crustáceos) da principal categoria específica capturada; (iii) principal categoria específica capturada; (iv) principal arte de pesca utilizada; (v) diversidade (número) de artes de pesca e meios de captura utilizados; (vi) estação do ano que ocorre a maior captura (Tabela 7). 
Tabela 7 - Caracterização da pesca dos municípios do litoral de Pernambuco. MD - meio de deslocamento; Tipo/tamanho tipo ou tamanho do meio de deslocamento; Grupo - grupo geral a que pertence a principal categoria específica de pescado capturada; Categoria - nomes vulgares das principais categorias específicas capturadas: Agulha - Hyporhamphus unifasciatus, Hemiramphus brasiliensis e Strongylura marina; Camarões - Penaiedae; Garajuba - Caranx crysos; Lagosta - Panulirus argus, Panulirus laevicauda e Scyllarides brasiliensis; Manjuba - Anchoa spp, Centengraulis edentulus, Anchoviella spp e Lycengraulis grossidens; Marisco - Anomalocardia flexuosa; Saramunete - Pseudupeneus maculatus; Sardinha - Sardinella brasiliensis; e Sirigado - Mycteroperca spp; Arte - principal arte de pesca utilizada; NA - número de artes de pesca utilizadas; Estação - estação do ano em que ocorrem os maiores desembarques.

\begin{tabular}{|c|c|c|c|c|c|c|c|}
\hline Município & $\mathrm{MD}$ & Tipo/tamanho & Grupo & Categoria & Arte & NA & Estação \\
\hline Itamaracá & motorizado & média & peixe & saramunete & $\begin{array}{l}\text { covo de } \\
\text { peixe }\end{array}$ & 14 & Primavera \\
\hline Paulista & motorizado & pequena & peixe & saramunete & $\begin{array}{l}\text { covo de } \\
\text { peixe }\end{array}$ & 9 & Primavera \\
\hline Olinda & motorizado & pequena & peixe & saramunete & $\begin{array}{l}\text { covo de } \\
\text { peixe }\end{array}$ & 11 & Primavera \\
\hline Recife & motorizado & média & peixe & sardinha & linha & 14 & Verão \\
\hline $\begin{array}{l}\text { Jaboatão dos } \\
\text { Guararapes }\end{array}$ & motorizado & média & peixe & sirigado & linha & 13 & primavera \\
\hline $\begin{array}{l}\text { Cabo de Santo } \\
\text { Agostinho }\end{array}$ & motorizado & média & peixe & garajuba & linha & 16 & Outono \\
\hline Ipojuca & motorizado & média & peixe & agulha & linha & 9 & primavera \\
\hline Sirinhaém & motorizado & média & crustáceo & camarões & rede & 18 & Verão \\
\hline Tamandaré & motorizado & média & crustáceo & camarões & linha & 18 & primavera \\
\hline São José & motorizado & média & crustáceo & lagosta & linha & 19 & primavera \\
\hline Goiana & $\begin{array}{c}\text { não- } \\
\text { motorizado }\end{array}$ & canoa & molusco & marisco & manual & 19 & Outono \\
\hline Itapissuma & $\begin{array}{c}\text { não- } \\
\text { motorizado }\end{array}$ & canoa & peixe & manjuba & mangote & 9 & Outono \\
\hline Igarassu & $\begin{array}{c}\text { não- } \\
\text { motorizado }\end{array}$ & terrestre & molusco & marisco & manual & 6 & Inverno \\
\hline Abreu e Lima & $\begin{array}{c}\text { não- } \\
\text { motorizado }\end{array}$ & canoa & molusco & marisco & rede & 3 & primavera \\
\hline Rio formoso & $\begin{array}{c}\text { não- } \\
\text { motorizado }\end{array}$ & canoa & molusco & marisco & manual & 10 & primavera \\
\hline
\end{tabular}

A análise de agrupamentos subdividiu os municípios em dois grupos abrangentes (Figura 5). O primeiro grupo foi formado pelos municípios de Goiana, Itapissuma, Igarassu, Abreu e Lima e Rio Formoso, onde predominou o uso de embarcações não motorizadas. O segundo grupo foi composto pelos municípios de Itamaracá, Paulista, Olinda, Recife, Jaboatão, Cabo, Ipojuca, Sirinhaém, Tamandaré e São José, onde as embarcações eram, em sua maioria, motorizadas.

Nesse nível de agregação, o município de Itapissuma, que pertence ao primeiro grupo, teve suas pescarias baseadas principalmente nos peixes, tendo se diferenciado dos demais municípios por ter os moluscos como principal categoria de pescado.

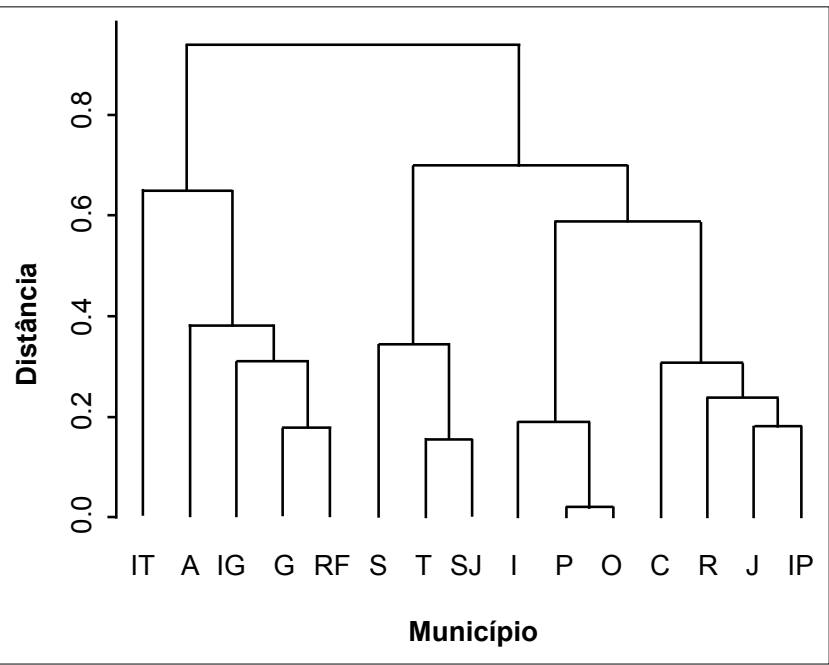

Figura 5 - Análise de agrupamento para os municípios litorâneos de Pernambuco considerando as diferentes características das atividades pesqueiras desenvolvidas. Cálculos baseados em distâncias euclidianas. Representações dos municípios são: G-Goiana; I - Itamaracá; IT - Itapissuma; IG - Igarassu; A - Abreu e Lima; P - Paulista; O Olinda; R - Recife; J - Jaboatão dos Guararapes; C - Cabo de Santo Agostinho; IP - Ipojuca; S - Sirinhaém; RF - RF - Rio Formoso; T - Tamandaré; e SJ - São José da Coroa Grande. 
Já o segundo grande grupo pode ser ainda dividido em dois subgrupos: o primeiro composto pelos municípios de Itamaracá, Paulista, Olinda, Recife, Jaboatão, Cabo e Ipojuca, onde as espécies mais desembarcadas foram de peixes (agulha, garajuba, saramunete, sardinha e sirigado); e o segundo composto pelos municípios de Sirinhaém, Tamandaré e São José, onde as espécies mais desembarcadas foram de crustáceos (camarões e lagosta). Nesse nível de agregação, os municípios de Itamaracá, Paulista e Olinda, tinham os covos como principal arte de pesca, diferenciando-se, ainda, dos outros quatro componentes desse subgrupo, por terem as linhas como principal arte de pesca.

\section{DISCUSSÃO}

Os anos de 2005 e 2006 foram os que apresentaram maiores desembarques, decorrentes, principalmente, do crescimento na captura da maioria das Famílias (e.g. Portunidae), especialmente a Veneridae (Tabela 5). Duas hipóteses podem ser sugeridas para explicar este fenômeno: a) o abrupto incremento da atividade pesqueira em meados da década de 2000; e b) falha amostral e subestimativas nos anos anteriores a 2005 e 2006.

A primeira hipótese parece ser menos plausível, pois há registros que indicam que a pesca em Pernambuco se encontra em declínio, e a importação de pescado seria a responsável pela maior parte do suprimento da demanda local (Barros et al., 2001). Vale destacar que os elevados valores de captura reportados a partir de 2004 são, em grande parte, decorrentes das produções obtidas pelos coletores manuais na exploração de invertebrados (famílias Veneridae, Ostreidae, Portunidae e Mytilidae) (Tabela 5). A coleta manual é uma atividade tradicional e há longa data a mariscagem de bivalves está entre as atividades de subsistência mais comuns nos ecossistemas costeiros (Dias et al., 2007). No início da década de 2000 havia registros de que a exploração de marisco já estava comprometida em diversas regiões do litoral brasileiro (Nishida et al., 2004).

A segunda hipótese parece mais plausível. As capturas de vários recursos, e em especial dos moluscos via coleta manual, parecem ter sido subestimadas em anos anteriores a 2005, especialmente no início da década de 2000. A estatística pesqueira oficial pode ter obtido melhor desempenho amostral, inclusive com a inserção do município de Abreu e Lima. Além disso, no relatório do Ibama/Cepene (2008) foi descrito a dificuldade do acompanhamento das coletas manuais. Em sendo verdadeira a hipótese de falha amostral, deduz-se que há um viés para cima na estatística de produção nos anos anteriores a 2005.

Os municípios de Itapissuma e Goiana foram os que mais se destacaram em Pernambuco, no que diz respeito aos totais capturados (Figura 1 B). A captura manual foi grande nesses dois municípios (Tabela 6) e o tipo de embarcação predominante é a canoa, que é útil em áreas abrigadas, mas inadequadas para regiões marinhas abertas.

Os estuários têm reconhecida importância em função de seus aspectos ecológicos, econômicos e sociais, destacando-se o seu papel como áreas reprodução de várias espécies como peixes, moluscos e crustáceos, e por darem suporte a cadeias alimentares diversificadas e complexas, que dependem da provisão de quantidades significativas de matéria orgânica e nutrientes (Braga et al., 2000; Day et al., 2012). A região estuarina associada ao Canal de Santa Cruz, que é o maior do Estado de Pernambuco (Moura, 2009), apresentando grande biodiversidade e servindo de fonte de renda, principalmente por meio da pesca e coleta de moluscos e crustáceos pelas comunidades do entorno (Lima \& Quimano, 2000). 
A abundância de moluscos é maior exatamente na região intermareal, na interface do ambiente terrestre e aquático (Nybakken, 2001).

Os municípios próximos a estuários têm a mariscagem como grande destaque (Ostini \& Poli, 1990). De fato, como apontado nos resultados deste trabalho, Goiana tem como principal categoria específica o marisco. Itapissuma apresenta um diferencial, pois explora intensamente no estuário a manjuba, além de marisco e outros bivalves.

Independente dos grupos de espécies explorados ficou evidente que os principais produtores de pescado dependem fundamentalmente da produtividade e funcionalidade do ambiente estuarino. A região estuarina, apesar de apresentar uma baixa abundância populacional que é característica de ambientes tropicais, é explorada pela pesca artesanal, com embarcações de pequeno porte e baixa produção (Lessa et al., 2006), e que tem se mostrado fundamental para a produção pesqueira pernambucana.

As embarcações tipo canoa, de pouca autonomia, foram as que corresponderam aos maiores desembarques em Pernambuco. Apesar de não ter predominância em todos os municípios, as canoas foram muito utilizadas em municípios de elevado volume de captura como Goiana e Itapissuma. Isto, aliado ao fato de que coletas manuais foram as que proporcionaram as maiores capturas no estado, confirma que a pesca em Pernambuco, até meados da década de 2000, era essencialmente artesanal, como destacado por Lessa et al. (2006; 2011). Portanto, dado o exposto, em Pernambuco, as pescarias de pequena escala, por sua importância socioeconômica, deveriam ser tratadas como prioridade nas políticas voltadas para o gerenciamento pesqueiro.

Os desembarques de peixes no Estado de Pernambuco, ao longo dos anos estudados, foram sempre superiores aos dos moluscos e crustáceos (Figura 4). Isto pode ser explicado pelo fato que a pesca pernambucana ocorre principalmente em zonas abrigadas de estuários, em que os peixes constituem o componente dominante da macrofauna da biota estuarina (Martino \& Able, 2003). Entre os moluscos e crustáceos, os estoques e as espécies exploradas são ainda bastante reduzidos, enquanto que o grupo geral de peixes apresenta maior diversidade, o que propicia capturas agregadas maiores. No entanto, comparado a outros Estados do Brasil como, por exemplo, os da região amazônica (e.g. Amazônia, Rondônia) cuja as capturas são praticamente realizadas sobre espécies de peixes, os percentuais capturados de Pernambuco são baixos, enquanto que comparativamente a participação, principalmente dos moluscos, são elevadas.

Os grupos específicos que mais se destacaram ocupam, na maioria, os níveis mais baixos na cadeia trófica (Tabela V e VI). As categorias marisco e ostra são bivalves filtradores. A categoria manjuba, que tem também importância destacada, é, segundo o Ibama/ Cepene (2008), correspondente a espécies da Família Engraulidae, as quais são peixes de pequeno porte que possuem hábitos costeiros (Carpenter, 2002). Os demais elementos que aparecem entre as cinco principais categorias capturadas foram o saramunete e os camarões. Os camarões, sendo a base de cadeia e o saramunete, Pseudupeneus maculatus, é uma espécie de peixe que se alimenta principalmente de invertebrados e crustáceos, com ajuda de barbilhões que lhe permite explorar o substrato (Gosline, 1984).

Em suma, a pescaria de Pernambuco, em geral, está em amparada na exploração de exemplares e espécies pequenas da base da cadeia trófica. Portanto, sugere-se investimentos em pesquisa voltados para a estrutura e funcionamento desses componentes na ecologia dos ambientes em que estão inseridos, e que sustentam as pescarias do estado.

Em Pernambuco, observou-se uma diferenciação quanto às características da atividade pesqueira desenvolvida nos diversos municípios (Figura 2 e 5, Tabela 4 e 7). 
Primeiramente, há dois grupos com embarcações de autonomias distintas, motorizadas ou não. A maior parte das pescarias do litoral norte pernambucano é realizada em mangues e nas zonas estuarinas, enquanto no litoral sul em zonas estuarinas e no mar de fora que é uma zona externa aos recifes (Lessa et al., 2006).

Esta diferença entre as áreas de pesca tem implicações quanto às embarcações e as principais espécies desembarcadas. Enquanto o grupo que utiliza comumente embarcações não motorizadas desembarca principalmente espécies estuarinas, de reduzido valor comercial individual (e.g. marisco e manjuba), o grupo que utiliza principalmente embarcações motorizadas, desembarca espécies marinhas de valor comercial individual superior, como o saramunete, que é um pescado destinado à exportação (Lessa et al., 2011). Neste caso, os custos maiores das embarcações motorizadas seriam compensados pelo maior valor do pescado.

Os dois grandes grupos de municípios podem ainda ser diferenciados em função da categoria específica mais capturada. Enquanto no primeiro grupo há um predomínio de marisco, que é um molusco, no segundo grupo predominam peixes e crustáceos. Portanto, as evidências apontam para a existência de um zoneamento nessa organização.

Os municípios do primeiro grupo, conhecidos por pescarias predominantemente feitas em estuários, utilizando canoas (Itapissuma, Abreu e Lima, Goiana, Igarassu e Rio Formoso), são quase todos localizados no litoral Norte. Na região Centro-Norte do estado predominaram as pescarias marinhas com uso frequente de covos (Itamaracá, Paulista e Olinda). Na região Central predominaram as pescarias marinhas com linhas (Recife, Cabo de Santo Agostinho, Jaboatão dos Guararapes e Ipojuca). Por fim, no sul do estado destacaram-se também as pescarias marinhas com elevadas capturas de crustáceos e a exploração de recursos pesqueiros relacionados a fundos sólidos (e.g. arrecifes e recifes).

No período de tempo avaliado para a pesca no litoral de Pernambuco, as estimativas nos anos anteriores a 2005 podem ter sido subestimadas, principalmente os dados relativos as capturas das espécies de coleta manual que corresponderam a um percentual elevado da produção do Estado. Entre essas espécies, o marisco teve destaque marcante, sendo predominantemente capturado no litoral Norte que é também a região em que se concentra os recursos mais desembarcados como, por exemplo, a manjuba. Desta forma, em função das diferenças entre os municípios litorâneos, o zoneamento das atividades pesqueiras deve ser levado em conta no processo de tomada de decisões e nas políticas de gestão das pescarias e de conservação dos recursos pesqueiros.

\section{REFERÊNCIAS}

Aragão, J.A.N.; Rocha, C.A.S.R.; Petrere Junior, M. Análise da consistência estatística do programa de coleta de dados de desembarque de pescado, executado pelo IBAMA no nordeste do Brasil. Boletim Técnico Científico do CEPENE, v.13, n 2, p. 97-127, 2005.

Barros, A.; Hazin, F.; Correia, S. Pedrosa, B.; Raposo, I. \& Filizola, M. Análise econômica da pesca Marítima de Pernambuco. Relatório de Pesquisa, FADE-UFPE. 250p, Recife, 2001.

Braga, E.S.; Bonetti, C.V.D.H.; Burone, L. \& Filho, J.B. Eutrophication and bacterial pollution caused by industrial and domestic wastes at the Baixada Santista Estuarine System Brazil. Mar. Pollut. Bull., v.40, n.2, p.165-173, 2000.

Carpenter, K.E. The Living Marine Resources for the Western Central Atlantic. v.2, Bony Fishes. Part 1 (Acipenseridae to Grammatidae). FAO Species Identification Guide for Fishery 
Purposes and American Society of Ichthyologists and Herpetologists. Special Publication n. 5, Rome, FAO. p. 601-1374, 2002

Day, J.W.; Kemp, W.M.; Yañez-Arancibia, A. \& Crump, B.C. Estuarine Ecology. 2a edição. 568 p., Wiley-Blackwell, 2012.

Dias, T.L.P.; Rosa, R.S.; Damasceno, L.C.P. Aspectos sócio-econômicos, percepção ambiental e perspectivas das mulheres marisqueiras da Reserva de Desenvolvimento Sustentável Ponta do Tubarão (Rio Grande do Norte, Brasil). Gaia Scientia, v.1, n.1, p.25-35, 2007.

Fao Fisheries Department. The ecosystem approach to fisheries. GAO Technical Guidelines for Responsible Fisheries. v.4, n.2, 112 p, 2003.

Gosline, W. A. Structure, function and ecology in the goatfishes (family Mullidae). Pac. Sci., v.38, p.312-323. 1984.

Ibama. Manual do Estatpesca. Fortaleza, CE. 57p, 1995.

Ibama/Cepene. Boletim estatístico da pesca marítima estuarina do nordeste do Brasil - 1999. 150 p, Tamandaré, 2000.

Ibama/Cepene. Boletim estatístico da pesca marítima estuarina do nordeste do Brasil - 2000. 69 p, Tamandaré, 2002.

Ibama/Cepene. Boletim estatístico da pesca marítima estuarina do nordeste do Brasil - 2001. 140 p, Tamandaré, 2003.

Ibama/Cepene. Boletim estatístico da pesca marítima estuarina do nordeste do Brasil - 2002. 209 p, Tamandaré, 2004.

Ibama/Cepene. Boletim estatístico da pesca marítima estuarina do nordeste do Brasil - 2003. 215 p, Tamandaré, 2005.

Ibama/Cepene. Boletim estatístico da pesca marítima estuarina do nordeste do Brasil - 2004. 191 p, Tamandaré, 2006.

Ibama/Cepene. Boletim estatístico da pesca marítima estuarina do nordeste do Brasil - 2005. 340 p, Tamandaré, 2007.

Ibama/Cepene. Boletim estatístico da pesca marítima estuarina do nordeste do Brasil - 2006. 385 p, Tamandaré, 2008.

Kruskal, W.H. \& Wallis, W.A. Use of ranks in one-criterion variance analysis. J. Am. Stat. Assoc., v.47, p.583-621, 1952.

Lessa, R.; Vieira, A.C.S.; Monteiro, A.; Santos, J.S.; Lima, M.M.; Cunha, E.J.; Souza-Junior, J.C.A.; Bezerra, S.; Travassos, P.U.P. \& Oliveira, A.B.R. Diagnóstico da pesca no litoral do estado de Pernambuco. in Isaac, V.J.; Martins, A.S.; Haimovici, M. \& Andriguetto-Filho, J.M. (eds). A pesca marinha e estuarina do Brasil no início do século XXI: Recursos, tecnologias, aspectos socioeconômicos e institucionais. Editora Universitária/UFPA, p.67-92, Belém, 2006.

Lessa, R.P.; Monteiro, A.; Duarte-Neto, P.J. \& Vieira, A.C. Análise Multidimensional dosSistemas de Produção Pesqueira do Estado de Pernambuco, Brasil. in Haimovici, M. (ed)., Sistemas Pesqueiros Marinhos e Estuarinos do Brasil. Editora da FURG. p. 41-54. Rio grande do Sul. 2011.

Lima, T. \& Quimano, T. Características socioeconômicas. in Barros, H.M.; Eskinazi-Lessa, E.; Macedo, S.J. \& Lima, T. (eds). Gerenciamento participativo de estuários e manguezais. Editora Universitária, p.181-225, Recife, 2000. 
Manly, B.F J. Multivariate Statistical Methods. $3^{\text {a }}$ edição. Boca Raton: Chapman \& Hall/CRC, $214 p, 2005$.

Martino, E.J. \& Able, K.W. Fish assemblages across the marine to low salinity transition zone of a temperate estuary. Estuar. Coast. Shelf Sci., v.56, p.969-987, 2003.

Moura, R.T. Aspectos Gerais da Hidrobiologia do Litoral Norte de Pernambuco -Brasil. Ibama, Brasília, 138 p, 2009.

Nybakken, J.W. Marine Biology: An Ecological Approach. 5 ed. Benjamin Cummings, San Francisco, 516 p, 2001.

Nishida, A.K.A.; Nordi, N. \& Alves, R.R.D.N. Abordagem etnoecológica da coleta de moluscos no litoral Paraibano. Trop Ocean. v.32, n.1, p.53-68, 2004.Ostini, S. \& Poli, C.R. A Situação do cultivo de moluscos no Brasil. in Hernandes, A.R. (ed). Cultivo de Moluscos em América Latina. Red. Regional de Entidades y Centros de Acuicultura de America Latina. Memorias segunda reunion grupo de trábalo técnico - ANCUD (Isla Chile - Chile) - CIID: 404, Bogotá. p. 311-325, 1990.

Policansky, D. Science and decision making in fisheries management. in Pitcher, T.J., Hart, P.J.B. \& Pauly, D. (eds). Reinventing Fisheries Management. Kluwer Academic Publishers, London, p. 57-71, 1998.

R CORE TEAM. R - A Language and Environment for Statistical Computing. 2017. Disponível em <https:/ / www.R-project.org/>. Acessado em: 20 dezembro 2017.

Shepherd, J.G. The Availability and Information Content of Fisheries Data. in May, R.M. (ed.). Exploitation of Marine Communities. Dahlem Konferenzen, Springer-Verlag, Berlin, p.95-109, 1984. 